\title{
Ocean sustainability: essential for blue planet
}

\author{
Naveen Kumar Arora ${ }^{1} \cdot$ Isha Mishra $^{2}$
}

Published online: 9 March 2020

(c) Society for Environmental Sustainability 2020

Oceans cover over $70 \%$ of earth's area which is more than two thirds of the planet, providing huge services to mankind and other life forms. But since recent past, these natural treasures are facing increasing constraints due to unprecedented anthropogenic activities which have negatively hampered their sustainability. Oceans are now being over-exploited for food supply, as transport of goods and humans, and a convenient dumping zone for various types of wastes. With technological advancements humans have accessed even the remotest parts of marine ecosystems. This has caused severe degradation of oceans, resulting in lack of replenishment and a catastrophe in making. Rising sea levels due to rapid pace of global warming, acidification due to increasing carbon emissions, unsustainable overfishing, and ocean pollution due to industrialization, agricultural wastes and oils spills are some of the major threats faced by marine life (Arora and Mishra 2019).

Reports claim that global mean sea level have risen by 8-9 inches since 1880 , mainly due to melting of ice sheets and glaciers and thermal expansions in sea water. It has also been reported that the year 2018 witnessed sea level rise of 3.2 inches which is the highest recorded (for a single year till that year) (https://www.climate.gov/news-features/under standing-climate/climate-change-global-sea-level). The Intergovernment Panel on Climate Change (IPCC) has predicted that even if the current greenhouse gas (GHG) emissions are reduced, the global mean sea level could still rise by 30 to $60 \mathrm{~cm}$ by 2100 (https://www.ipcc.ch/2019/09/25/ srocc-press-release/). Similarly, Kwok (2018) reported that thickness of Arctic ice sheet has been lost by $50 \%$ during 1977-2017. In the same context, loss of Antarctic ice sheet has tripled between 2007 and 2016 (IPCC 2019). The rise in

Naveen Kumar Arora

nkarora.bbau@gmail.com

1 Department of Environmental Science, School for Environmental Science, BBA University, Lucknow, UP, India

2 Department of Environmental Microbiology, BBA University, Lucknow, UP, India sea level will threaten the human population and infrastructure, particularly in coastal regions, and especially during deadly cyclones/storms or tsunamis, which can cause havoc in the mainland and especially in Small Island Development States (SIDS) which have low resilience to such extreme weather events. On the other hand, high levels of carbon emissions are causing acidification of oceans. Unchecked pace of deforestation, burning of fossil fuels, shrinkage in available land due to population explosion, industrialization, are some of the key factors responsible for increasing $\mathrm{CO}_{2}$ levels. Oceans are regarded as sinks of $\mathrm{CO}_{2}$ and as it dissolves in water, formation of carbonic acid takes places decreasing the $\mathrm{pH}$. Ocean acidity is projected to increase by up to $0.042 \mathrm{pH}$ units by 2100 (Gaines et al. 2019). These alterations in chemistry of ocean systems adversely affect sea creatures such as corals, oysters, sea urchins, sea shells and other calcareous phytoplanktons. Acidification also affects the behaviour, growth and reproduction process in marine life. This can have profound effects on markets based on marine products. Moreover, global warming is also interrupting the circulation pattern of the ocean known as 'global conveyor belt' which is responsible for maintaining equilibrium in heat distribution on the globe.

The injudicious amount of pollution faced by marine environment has adverse effects on the biology of oceans which has entered at several levels of food chain. The human activities on land are the major drivers of pollution in water bodies. Waste runoff from agricultural farms (e.g. fertilizers) trigger the formation of algal blooms, resulting in eutrophication of oceans, suffocating the marine life. Moreover, release of contaminants such as heavy metals, petroleum hydrocarbons, pesticides, sewage and radioactive disposal get absorbed by tiny planktons, which when consumed by other small fishes enter the food chain and get biomagnified at different trophic levels. Consumption of these infected sea foods by humans cause genetic disorders, cancer, and infertility, to name a few. Plastic pollution is another menace playing havoc in oceans which has resulted in great loss of ecosystem services on the whole. A report by Our World in Data estimates that about $80 \%$ of plastic pollution in oceans 
comes from land based sources which travel through various coastlines, tides and river channels and remaining $20 \%$ comes from marine sources (such as abandoned fishing nets, lines, vessels and so on) (https://ourworldindata.org/plasticpollution). After entry in the ocean body, plastics get accumulated in the basins causing plethora of adversities to the biological entities. According to a report of Eriksen et al. (2014), about 269,000 tonnes of plastics (more than 5 trillion) were estimated on the surface of the oceans with highest quantities prevailing in the Northern Hemisphere (due to majority of anthropogenic activities in this region). Over the course of time, plastics get fragmented into smaller forms known as microplastics, which range from $0.1 \mu \mathrm{m}$ to $5 \mathrm{~mm}$, and remain in the oceanic ecosystem for the long period of times (Beaumont et al. 2019). These microplastics together with persistant organic pollutants (POPs), polyaromatic hydrocarbons (PAHs) and other xenobiotic contaminants become more complex and hazardous, adding to a myriad of adversities in marine life. Invasion of microplastics have now been identified in the pristine Arctic Sea ice as a result of atmospheric and other modes of transport. Research studies have shown that substantial amount of microplastics i.e. approximately 12,000 (microplastic) particles per ounce of melted ice were identified in the region which is magnifying like a big threat to this vulnerable ecosystem (https:// www.nationalgeographic.com/environment/2019/08/micro plastics-found-in-arctic-snow/) The 'Great Pacific Garbage Patch' (GPGP) is another glaring example in this context which is the resultant of severe plastic accumulation (https ://ourworldindata.org/plastic-pollution). Recent studies have claimed that the rate of plastic accumulation in GPGP is continuously increasing at an alarming rate and is like a drifting island of pollutants including (apart from plastics) toxicants such as heavy metals, e-wastes etc. Plastics also stimulate formation of bacterial biofilms by potential opportunistic pathogenic species, as a result of accessible nutrition accumulation and hence result in disease dispersal along the water current which can result in epidemics in coastal regions. These biofilms can also translocate diverse types of toxic pollutants to different parts of the globe including the non-human habitats such as Arctic and Antarctic. Spillage of oils in marine environment is another issue that needs to be taken into account. Oil spills in ocean create a hydrophobic layer of oil over sea water which cuts off atmospheric oxygen from entering into oceans resulting in hypoxic zones. Studies reveal that in last 5 years, nearly 40,000 tonnes of oil was leaked in marine ecosystems due to damaged tankers, accidental spillage and offshore mining.

Overfishing is the next major threat to the oceanic biodiversity. It is difficult to estimate the accurate worth of the services provided by oceans, but according to the report of United Nations Trade and Development (UNCTAD) (2014), roughly around 350 million jobs are associated to oceans which include fishing, aquaculture, tourism and research and development activities. In addition, over 1 billion people depend on fish as their sole source of protein (https:// unctad.org/en/PublicationsLibrary/ditcted2014d5_en.pdf). A global assessment report by Intergovernmental SciencePolicy Platform on Biodiversity and Ecosystem Services (IPBES) (2019) has stated that around 30\% reef forming corals and more than a third of marine species are under threat due to the impact of anthropogenic activities (https ://www.un.org/sustainabledevelopment/blog/2019/05/natur e-decline-unprecedented-report/). World Wide Fund (WWF) reports that about one-third of fish stocks are consumed in an unsustainable manner and currently this has reached beyond the replenishing capacities (https://www.worldwildlife.org/ threats/overfishing). In addition, UN report suggests that climate change and acidification has further exacerbated the situation and can bring about 3 to $25 \%$ decline in ocean biomass by the end of this century (https://www.seafoodsou rce.com/news/environment-sustainability/un-report-ocean -biodiversity-in-peril-to-due-overfishing-and-climate-chang e). Illegal killing of important and apex species such as whales, dolphins, turtles, seals, sharks and coral reefs for various economic purposes and anthropogenic activities are among other concerns which have dwindled the population of these species in oceans. These sea creatures possess inherent metabolic ability to store and sequester carbon, hence an abrupt decrease in their population may have deleterious consequences on carbon concentration in the ocean and atmosphere (Pershing et al. 2010).

To protect and conserve the services provided by oceans, we need to set strict measures and regulations. Goal 14 of United Nations Sustainable Development Goals (SDGs) 2030 is dedicated for restoration and protection of marine ecosystems. Unfortunately, only $3.4 \%$ of oceans are protected worldwide at present and therefore, construction of marine protected areas and other spatial protected zones should be the key target to reduce the overexploitation of ocean services. Employing biological and eco-friendly interventions in agriculture, food production, energy and fuel requirements, alternatives of plastics can reduce the risk of chemical and pollutants runoff in oceans. Biotechnological interferences such as cultivation and conservation of germplasms, especially of endangered and threatened species can have positive impact on species diversity in the continuously changing environment. Setting metagenomic libraries or gene banks to maintain a genetic stock of the indigenous ocean resources can also play a crucial role. Oceans have huge untapped resources which can be of great use for sustainable industrial production, for example of enzymes, pharmaceuticals, biofuels, alternative food, bio-energy, etc. But these need to be tapped first. Hence, it becomes important to develop novel technologies to identify and utilize the untapped biodiversity, mainly the microbial for green and 
sustainable alternatives. Omics techniques can be of great use in identifying the unknown microbes, their genes and metabolites. However, novel culture techniques need to be developed as well so that the un-culturable microbes can be grown and cultivated in laboratories and industries so as to utilize their full potential. Inoculation of microbial genes of interest through genetic manipulation in marine species e.g. coral reefs can provide tolerance to them in extreme weather events (Damjanovic et al. 2017). International repositories dedicated for conservation of marine life, importantly microbes and algae can be set up around biodiversity hot spots. Microbe-based remediation techniques such as use of allochthonous and autochthonous microbial communities and their metabolic products (e.g. biosurfactants) for removal of pollutants are already being exploited to remove marine pollution. Bioremediation is not only cost effective and ecofriendly but can also maintain sustainability of ocean ecosystems (Arora et al. 2018). However, there is need to improve and utilize this green technology so as to clear the marine ecosystems of diverse types of pollutants. Application of genomic techniques such as monitoring through eDNA and DNA barcoding can also play major role in combating unreported and illegal trading of marine resources (Novak et al. 2020). In this regard, CRISPR-Cas9 technology is particularly important which can detect target species with high specificity and in a short timeframe (Baerwald et al. 2019). Subsidies provided to the fishing industry need to be revaluated. This will reduce overfishing and help in maintaining the population. Improving the traceability of unregulated fishing fleets should end through proper policing. Single use plastic should be banned and a proper regulation on its use is urgently needed. Optimization of resources provided by oceans and marine ecosystems beyond a certain limit is necessary to sustain growth, increase food security and livelihood. Precise data mining by monitoring marine eso-systems is also required for proper assessment of the situation. Remote sensing and geographical information system (GIS) can be helpful tools to locate, investigate and manage the complexities of the constraints and pressures on marine life. This kind of real time monitoring and surveillance will also mitigate disease outbreaks and conservation of marine species. International Conventions from governing bodies should be ratified to increase awareness regarding marine pollution and its global consequences. Stringent laws should be formulated to safeguard the ocean's resources and maintain integrity of environment. Strategies related to litter control are needed to reduce the risk of increasing pollution levels in ocean system. Every nation and organization needs to work in tandem to sustain the oceans which control the climate, biodiversity and life on earth.

\section{References}

Arora NK, Mishra I (2019) United Nations Sustainable Development Goals 2030 and environmental sustainability: race against time. Environ Sustain 2:339-342

Arora NK, Fatima T, Mishra I, Verma M, Mishra J, Mishra V (2018) Environmental sustainability: challenges and viable solutions. Environ Sustain 1(4):309-340

Baerwald M, Goodbla A, Gootengerg J, Abudayyeh O, Schreier A (2019) Fast and easy: CRISPR-based assays for rapid and accurate species genetic identification. In Proceedings of American Fisheries Society (AFS) and the Wildlife Society Joint Conference, Reno, NV, USA

Beaumont NJ, Aanesen M, Austen MC, Börger T, Clark JR, Cole M, Hooper T, Lindeque PK, Pascoe C, Wyles KJ (2019) Global ecological, social and economic impacts of marine plastic. Mar Pollut Bull 142:189-195

Damjanovic K, Blackall LL, Webster NS, van Oppen MJH (2017) The contribution of microbial biotechnology to mitigating coral reef degradation. Microb Biotechnol 10(5):1236-1243

Eriksen M, Lebreton LC, Carson HS, Thiel M, Moore CJ, Borerro JC, Galgani F, Ryan PG, Reisser J (2014) Plastic pollution in the world's oceans: more than 5 trillion plastic pieces weighing over 250,000 tons afloat at sea. PLoS ONE 9(12):e11191

Gaines S, Cabral R, Free C, Golbuu Y et al (2019) The expected impacts of climate change on the ocean economy. World Resources Institute, Washington, DC. https://www.oceanpanel .org/expected-impacts-climate-change-ocean-economy

IPCC (2019) IPCC Special Report on the Ocean and Cryosphere in a Changing Climate (SROCC). Edited by Pörtner HO, Roberts DC, Masson-Delmotte V, Zhai P, Tignor M, Poloczanska E, Mintenbeck K et al. Intergovernmental Panel on Climate Change, Geneva

Kwok R (2018) Arctic sea ice thickness, volume, and multiyear ice coverage: losses and coupled variability (1958-2018). Environ Res Lett 13(10):105005

Novak BJ, Devaughan F, Maloney TH (2020) Transforming ocean conservation: applying the genetic rescue toolkit. Genes 11(2):209

Pershing AJ, Christensen LB, Record NR, Sherwood GD, Stetson PB (2010) The impact of whaling on the ocean carbon cycle: why bigger was better. PLoS ONE 5(8):e12444

Publisher's Note Springer Nature remains neutral with regard to jurisdictional claims in published maps and institutional affiliations. 